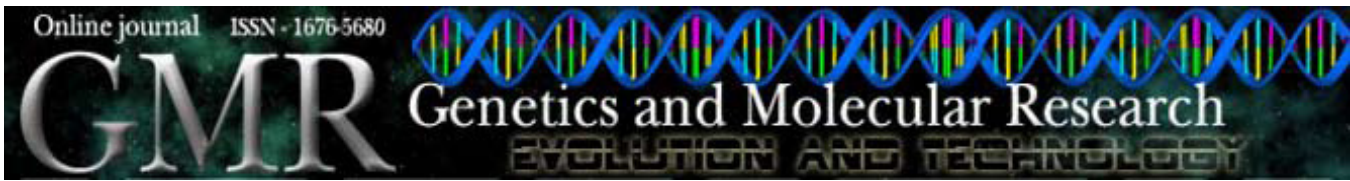

\title{
Primary open angle glaucoma was not found to be associated with $p 53$ codon 72 polymorphism in a Brazilian cohort
}

\author{
R.E. Silva ${ }^{1,2 *}$, J.T. Arruda ${ }^{3 *}$, F.W. Rodrigues ${ }^{1,2}$ and K.K.V.O. Moura ${ }^{2,3}$ \\ ${ }^{1}$ Pronto Clínica de Olhos, Goiânia, GO, Brasil \\ ${ }^{2}$ Programa de Pós-Graduação Stricto Sensu, Mestrado em Genética, \\ Goiânia, GO, Brasil \\ ${ }^{3}$ Departamento de Biologia, Universidade Católica de Goiás, \\ Núcleo de Pesquisas Replicon, Goiânia, GO, Brasil \\ *These authors contributed equally to this study. \\ Corresponding author: K.K.V.O. Moura \\ E-mail: katiakarinav@yahoo.com.br; jalsitacon@yahoo.com.br
}

Genet. Mol. Res. 8 (1): 268-272 (2009)

Received December 23, 2008

Accepted January 6, 2009

Published March 3, 2009

\begin{abstract}
Primary open angle glaucoma (POAG) is the most common type of glaucoma. The p53 codon 72 Arg-Pro (CGC to CCC) polymorphism of exon 4 affects various biological properties; recently, it was reported that this polymorphism affects the ability to induce apoptosis in vitro. Various genotypes have been found to be significantly associated with POAG. We examined the distribution of this polymorphism in 104 unrelated POAG patients and in 58 normal healthy individuals without history of POAG at the Pronto Clínica de Olhos in Goiânia, Brazil. The controls were recruited among individuals undergoing ophthalmological examination. Their genomic DNA was analyzed for $p 53$ gene codon 72 polymorphism by polymerase chain reaction. The Arg72 allele was more common than the Pro72 allele in both groups. There was no significant difference in the distribution of the codon 72 polymorphism between groups $(\mathrm{P}=0.3311)$. The genotype distribution in the POAG group was 23.07 Arg homozygote, 75 heterozygote, and 1.93\% Pro homozygote, while in the control group it was 31.04 Arg homozygote, 68.96 heterozygote,
\end{abstract}


and $0 \%$ Pro homozygote. We concluded that the $p 53$ codon 72 Arg/Pro polymorphism is not associated with glaucoma in Brazilian patients.

Key words: Primary open angle glaucoma; p53 codon 72 polymorphism

\section{INTRODUCTION}

Glaucoma is an optic neurodegenerative disease and is the second leading cause of bilateral blindness worldwide, after cataracts (Povoa et al., 2006). Primary open angle glaucoma (POAG) is the most common type, accounting for over half of all cases (Acharya et al., 2002). It is characterized by progressive excavation of the optic disc, frequently associated with loss of retinal nerve fibers, leading to visual field defects (Weinreb and Khaw, 2004); however, the initial development of this disease is not yet completely understood. It is possible that genetic alterations could be responsible for the initiation of a sequence of events that lead to higher resistance in aqueous humor drainage, as well as higher optic disc head susceptibility to intraocular pressure.

The major risk factors for POAG include a family history of this disease, high intraocular pressure, advanced age, certain ethnic groups, diabetes mellitus, impaired vascular function, and interaction of multiple genes (Morrison et al., 2005). This disease has been identified as one of the most important causes of irreversible vision loss, especially in African-Americans, in whom it is responsible for up to $19 \%$ of blindness in adults over 40 years of age (Povoa et al., 2006). Approximately half of POAG patients have a family history of glaucoma; early detection of disease is critical for avoiding glaucomatous damage and for minimizing irreversible vision loss (Vegini et al., 2008).

The tumor suppressor gene $p 53$ is a single copy gene located on the short arm of chromosome 17p13.1 (Storey et al., 1998). It consists of 11 exons, resulting in a 2629-bp transcript and a 393-amino acid protein. It is considered to be the guardian of the genome and is essential for the preservation of genome integrity. In response to DNA damage, the $p 53$ gene may arrest cell cycle progression in the late G1 phase, thus allowing the DNA to be repaired before its replication; if the damage is too extensive to be repaired it induces apoptosis by upregulating the pro-apoptotic gene $B a x$ and downregulating the expression of the antiapoptotic gene $\mathrm{Bcl}-2$ (Ressiniotis et al., 2005).

The p53 codon 72 Arg-Pro (CGC to CCC) polymorphism of exon 4 (National Center for Biotechnology Information single-nucleotide polymorphism identification number rs1042522; Matlashewski et al., 1987) has been shown to affect biological properties; recently, it was found that this polymorphism alters the ability to induce apoptosis in vitro (Tsai et al., 2004). It has been proposed that genomic instability of $p 53$ gene in other disease processes means that it also has a role in glaucomatous neuropathy (Dimasi et al., 2005).

The $p 53$ gene has been subject to many epidemiological studies that explore the possible association of this polymorphism with risk of different diseases; however, the results have remained inconclusive and the major risk factors for glaucoma are still the ethnicity of the population (Dimasi et al., 2005; Vegini et al., 2008). We examined polymorphism in exon 4 of the $p 53$ gene in Brazilian POAG patients and in a control group. 


\section{MATERIAL AND METHODS}

\section{Study population}

Blood samples were collected from 104 unrelated Brazilian POAG patients from the Pronto Clínica de Olhos in Goiânia. As a control, 58 normal healthy individuals without history of POAG were chosen among other patients attended at the same clinic. All patients were given an ophthalmologic examination, which included intraocular pressure, visual acuity, automated perimetry, gonioscopy, optic disc examination, and retinal examination. Prior to sample collection, written informed consent was obtained from all individuals. The internal review committee on research using human subjects cleared the project after due deliberations.

\section{Molecular analysis}

The genomic DNA was extracted from peripheral blood with the Illustra ${ }^{\mathrm{TM}}$ Blood Genomic DNA kit (GE HealthCare, USA). In the analysis of the $p 53$ gene codon 72 polymorphism, the primer Pro-72 (F-5' GCC AGA GGC TGC TCC CCC -3' and R-5' ATC TAC AGT CCC CCT TGC CG -3') was designed for $p 53$ codon 72 in the proline form and Arg-72 (F-5' CTG GTG CAG GGG CCA CGC -3' and R-5' CGT GCA AGT CAC AGA CTT -3') in the arginine form, according to the procedure described by Storey et al. (1998). PCR were carried out based on Lin et al. (2002). The PCR products were loaded on $2 \%$ agarose gel containing ethidium bromide for electrophoresis. After electrophoresis, the gels were stained with ethidium bromide and photographed under UV light (Figure 1).

Statistical analysis for the relative risk of $p 53$ codon 72 in control and POAG groups was compared using the $\chi^{2}$ test. Results were considered to be significant when the probability of findings occurring by chance was less than $5 \%(\mathrm{P}<0.05)$.

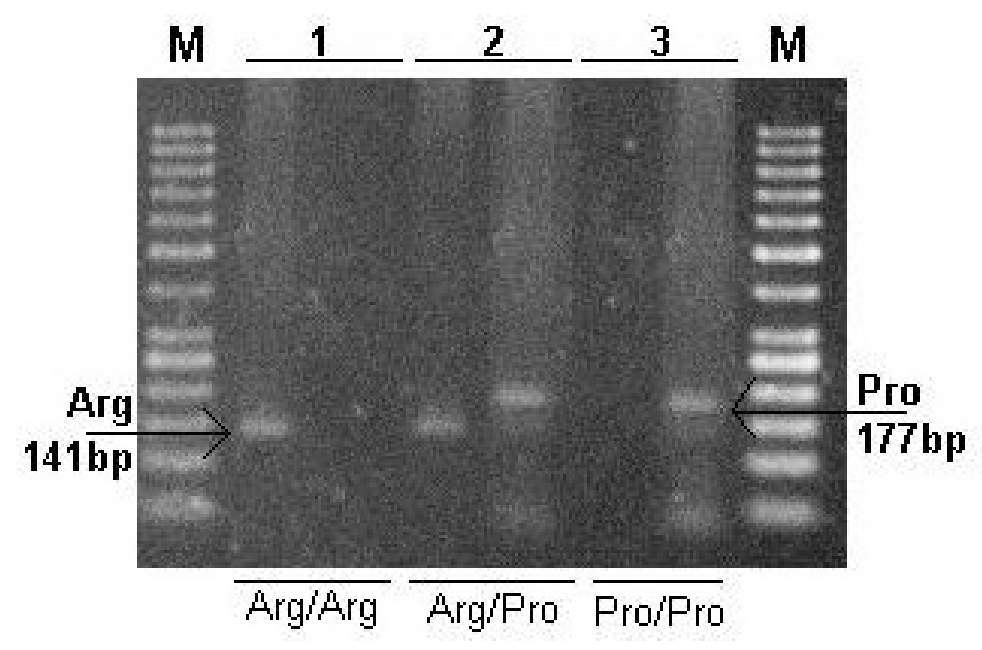

Figure 1. Detection of the $p 53$ codon 72 polymorphism on a $2 \%$ agarose gel with ethidium bromide after polymerase chain reaction amplification. $\mathrm{M}=$ molecular weight marker, 50-bp DNA ladder (Invitrogen). Lane $1=$ Arg-Arg homozygote; lane 2 = Arg-Pro heterozygote, and lane 3 = Pro-Pro homozygote. The Arg allele: $141 \mathrm{bp}$ and the Pro allele: $177 \mathrm{bp}$. 


\section{RESULTS}

The 104 POAG patients ranged in age from 13 to 87 years (mean 60.23 years old) and were unrelated. There were 50 females and 54 males. The 58 volunteers ranged in age from 18 to 77 years (mean age 44.95 years old) and were free from any ophthalmic diseases. There were 36 females and 22 males.

The Arg 72 allele was more common than the Pro72 allele in each group (Table 1). The distribution of the codon 72 polymorphism was not significantly different between groups $(\mathrm{P}=0.3311)$.

Table 1. Genotype distribution and allelic frequencies of $p 53$ codon 72 polymorphism in primary open angle glaucoma patients (POAG) and controls.

\begin{tabular}{|c|c|c|c|c|c|c|c|}
\hline \multirow[t]{2}{*}{ Group } & \multicolumn{4}{|c|}{ Genotype } & \multicolumn{3}{|c|}{ Allele frequency } \\
\hline & Arg-Arg & Arg-Pro & Pro-Pro & Number of individuals & ARG & PRO & Number of alleles \\
\hline POAG & $23.1 \%$ & $75 \%$ & $1.9 \%$ & 104 & $60.5 \%$ & $39.5 \%$ & 208 \\
\hline Control & $31 \%$ & $69 \%$ & $0 \%$ & 58 & $65.5 \%$ & $34.5 \%$ & 116 \\
\hline
\end{tabular}

\section{DISCUSSION}

One of the most well-studied $p 53$ gene polymorphisms is Arg72Pro, which affects the structure of the protein. The $p 53$ gene plays an important role in cell cycle control and can act as a transcription factor by binding to a p53-specific DNA consensus sequence in responsive genes (Tsai et al., 2004). The mutant or inactivated p53 protein fails to initiate the apoptotic process; consequently the cells proliferate in an uncontrolled manner (Weishaupt et al., 2003). In contrast, in neurodegenerative processes (Funayama et al., 2004) and toxic neuronal injury, the $p 53$ gene is upregulated in response to cellular stress, thereby promoting cell death through apoptosis. This raises the possibility that functional genetic variants of $\mathrm{p} 53$ protein influence the rate of neuronal cell loss in a number of neurodegenerative disorders, including POAG (Levkovitch-Verbin et al., 2006).

These two variant protein forms may behave differently. The Pro allele is associated with increased transcription of $p 53$ target genes via greater binding to transcriptional machinery and thus shows higher rates of $\mathrm{G}_{1}$ arrest than the Arg allele (Pim and Banks, 2004). In contrast, the Pro allele is less efficient in suppressing transformation (likely due to reduced apoptotic potential) than the Arg allele (Dumont et al., 2003). The Arg allele increases the ability of p53 to locate to mitochondria and induces cellular death, whereas the Pro allele exhibits a lower apoptotic potential and increases cellular arrest at $\mathrm{G}_{1}$ of the cell cycle (Bergamaschi et al., 2006).

We did not observe any significant difference in the distribution of the $p 53$ codon 72 polymorphism between the control group and POAG patients. Lin et al. (2002) analyzed 58 Chinese patients with POAG and found that the Pro72 polymorphism was significantly more common in patients than in controls $(\mathrm{P}=0.00782)$. In 67 cases of POAG in India, Acharya et al. (2002) found no association with glaucoma with codon 72 or intron 3 16-bp duplication polymorphisms $(\mathrm{P}=0.5627)$. Ressiniotis et al. (2004) studied these same polymorphisms in 140 British POAG patients; they observed a significant difference in the $p 53$ haplotype distribution $(\mathrm{P}<0.0001)$. Arginine at codon 72 was significantly more common in patients than controls. 
Dimasi et al. (2005) analyzed 345 Australians with POAG for the same polymorphisms and found no evidence for Hardy-Weinberg disequilibrium of $p 53$ gene haplotypes between groups $(\mathrm{P}=0.35)$. These different findings may be due to racial variation or may reflect sample bias.

The $p 53$ codon $72 \mathrm{Arg} /$ Pro polymorphism was not found to be associated with glaucoma in Brazilian patients.

\section{ACKNOWLEDGMENTS}

Research supported by Universidade Católica de Goiás, Goiânia, Brazil (UCG/ PROPE/MGene). We are grateful to the Pronto Clínica de Olhos for allowing us to conduct this research and for support. J.T. Arruda was the recipient of a Conselho Nacional de Desenvolvimento Científico e Tecnológico (CNPq) fellowship.

\section{REFERENCES}

Acharya M, Mitra S, Mukhopadhyay A, Khan M, et al. (2002). Distribution of p53 codon 72 polymorphism in Indian primary open angle glaucoma patients. Mol. Vis. 8: 367-371.

Bergamaschi D, Samuels Y, Sullivan A, Zvelebil M, et al. (2006). iASPP preferentially binds p53 proline-rich region and modulates apoptotic function of codon 72-polymorphic p53. Nat. Genet. 38: 1133-1141.

Dimasi DP, Hewitt AW, Green CM, Mackey DA, et al. (2005). Lack of association of p53 polymorphisms and haplotypes in high and normal tension open angle glaucoma. J. Med. Genet. 42: e55.

Dumont P, Leu JI, Della PA III, George DL, et al. (2003). The codon 72 polymorphic variants of p53 have markedly different apoptotic potential. Nat. Genet. 33: 357-365.

Funayama T, Ishikawa K, Ohtake Y, Tanino T, et al. (2004). Variants in optineurin gene and their association with tumor necrosis factor-alpha polymorphisms in Japanese patients with glaucoma. Invest. Ophthalmol. Vis. Sci. 45: 4359-4367.

Levkovitch-Verbin H, Dardik R, Vander S, Nisgav Y, et al. (2006). Experimental glaucoma and optic nerve transection induce simultaneous upregulation of proapoptotic and prosurvival genes. Invest. Ophthalmol. Vis. Sci. 47: 2491-2497.

Lin HJ, Chen WC, Tsai FJ and Tsai SW (2002). Distributions of p53 codon 72 polymorphism in primary open angle glaucoma. Br. J. Ophthalmol. 86: 767-770.

Matlashewski GJ, Tuck S, Pim D, Lamb P, et al. (1987). Primary structure polymorphism at amino acid residue 72 of human p53. Mol. Cell Biol. 7: 961-963.

Morrison JC, Johnson EC, Cepurna W and Jia L (2005). Understanding mechanisms of pressure-induced optic nerve damage. Prog. Retin. Eye Res. 24: 217-240.

Pim D and Banks L (2004). p53 polymorphic variants at codon 72 exert different effects on cell cycle progression. Int. J. Cancer 108: 196-199.

Povoa CA, Malta RF, Rezende MM, de Melo KF, et al. (2006). Correlation between genotype and phenotype in primary open angle glaucoma of Brazilian families with mutations in exon 3 of the TIGR/MYOC gene. Arq. Bras. Oftalmol. 69: 289-297.

Ressiniotis T, Griffiths PG, Birch M, Keers S, et al. (2004). Primary open angle glaucoma is associated with a specific p53 gene haplotype. J. Med. Genet. 41: 296-298.

Ressiniotis T, Griffiths PG, Keers SM, Chinnery PF, et al. (2005). A polymorphism at codon 31 of gene p21 is not associated with primary open angle glaucoma in Caucasians. BMC Ophthalmol. 5: 5.

Storey A, Thomas M, Kalita A, Harwood C, et al. (1998). Role of a p53 polymorphism in the development of human papillomavirus-associated cancer. Nature 393: 229-234.

Tsai FJ, Lin HJ, Chen WC, Tsai CH, et al. (2004). A codon 31ser-arg polymorphism of the WAF-1/CIP-1/p21/tumour suppressor gene in Chinese primary open-angle glaucoma. Acta Ophthalmol. Scand. 82: 76-80.

Vegini F, Figueiroa FN, Lenci RF, Garcia ND, et al. (2008). Prevalence of open angle glaucoma in accompanying first degree relatives of patients with glaucoma. Clinics 63: 329-332.

Weinreb RN and Khaw PT (2004). Primary open-angle glaucoma. Lancet 363: 1711-1720.

Weishaupt JH, Diem R, Kermer P, Krajewski S, et al. (2003). Contribution of caspase-8 to apoptosis of axotomized rat retinal ganglion cells in vivo. Neurobiol. Dis. 13: 124-135. 